\title{
The Nimbleness of Neoliberalism in Queerness and EDI policy
}

Gillian Robinson

Educational Policy Studies, University of Alberta

\section{Key findings:}

- Analyzing the conditions that create and entrench a queer and non-queer binary

- Questioning if queer-inclusive policy disrupts this binary

-Wondering what purposes this binary continues to serve

\section{Abstract}

I attempt to explore how queerness has been mobilized in this current historical context of neoliberal Equity, Diversity, and Inclusion (EDI) policies. First, I will briefly overview the historical materialism of queerness under racial colonial capitalism. I will discuss what the lenses of surplus populations and social reproduction can and cannot help us see about queerness. Then, I will discuss how the mechanisms of neoliberalism both mobilize and repress queerness, as convenient. Finally, I will interrogate how (queer) EDI policy is implemented and negotiated in educational institutions, and situate it specifically within $\mathrm{K}-12$ schools in Alberta.

Keywords: Queer-inclusive education, Historical materialism, queer theory, queer, queernes

Cite as: Robinson G. 2021. The nimbleness of neoliberalism in queerness and EDI policy. Alberta Academic Review, Vol 4 (1): 7, EEGSA-SEGSA Special Issue: Remote Connections, DOI: 10.29173/aar127 